\title{
Speculative bubbles and the cross- sectional variation in stock returns
}

Article

Accepted Version

Anderson, K. and Brooks, C. (2014) Speculative bubbles and the cross-sectional variation in stock returns. International Review of Financial Analysis, 35. pp. 20-31. ISSN 1057-5219 doi: https://doi.org/10.1016/j.irfa.2014.07.004 Available at https://centaur.reading.ac.uk/38399/

It is advisable to refer to the publisher's version if you intend to cite from the work. See Guidance on citing.

Published version at: http://dx.doi.org/10.1016/j.irfa.2014.07.004

To link to this article DOI: http://dx.doi.org/10.1016/j.irfa.2014.07.004

Publisher: Elsevier

All outputs in CentAUR are protected by Intellectual Property Rights law, including copyright law. Copyright and IPR is retained by the creators or other copyright holders. Terms and conditions for use of this material are defined in the End User Agreement.

\section{www.reading.ac.uk/centaur}

\section{CentAUR}

Central Archive at the University of Reading

Reading's research outputs online 
NOTICE: this is the author's version of a work that was accepted for publication in the International Review of Financial Analysis. Changes resulting from the publishing process, such as peer review, editing, corrections, structural formatting, and other quality control mechanisms may not be reflected in this document. Changes may have been made to this work since it was submitted for publication. A definitive version was subsequently published in the International Review of Financial Analysis, 35, 20-31 (2014), DOI:

http://dx.doi.org/10.1016/i.irfa.2014.07.004 


\title{
Speculative Bubbles and the Cross-Sectional Variation in Stock Returns
}

\author{
Keith Anderson ${ }^{\mathrm{a}}{ }^{*}$ and Chris Brooks ${ }^{\mathrm{b}}$ \\ ${ }^{a}$ The York Management School, University of York, Freboys Lane, York YO10 5GD, England \\ ${ }^{\mathrm{b}}$ ICMA Centre, Henley Business School, University of Reading, Whiteknights, Reading RG6 \\ 6BA, England
}

June 2014

\begin{abstract}
Evidence suggests that rational, periodically collapsing speculative bubbles may be pervasive in stock markets globally, but there is no research that considers them at the individual stock level. In this study we develop and test an empirical asset pricing model that allows for speculative bubbles to affect stock returns. We show that stocks incorporating larger bubbles yield higher returns. The bubble deviation, at the stock level as opposed to the industry or market level, is a priced source of risk that is separate from the standard market risk, size and value factors. We demonstrate that much of the common variation in stock returns that can be attributable to market risk is due to the co-movement of bubbles rather than being driven fundamentals.
\end{abstract}

Keywords: speculative bubbles, asset pricing, stock returns, CAPM, cross-sectional variation JEL Classifications: G11, G14, C21, C22

Acknowledgements: We are grateful to Rajesh Tharyan for providing a list of SEDOL codes matched with those from Datastream, and to Apostolos Katsaris, discussions with whom helped to shape the ideas for this paper. We are also grateful to conference participants at the European Financial Management Association 2013 conference and the British Accounting and Finance Association 2013 conference for their useful comments. We thank two anonymous referees for their comments on a previous version of the paper.

\footnotetext{
•Corresponding author tel: (+44) 1904 325001; e-mail: keith.anderson@york.ac.uk
} 


\section{Introduction}

Why do some stocks generate higher returns than others? Addressing this apparently simple question has been the focus of a vast amount of empirical research spanning almost half a century. Of the more popular approaches to modelling the returns on risky assets that have been proposed, a fruitful family of models stem from a modified version of the capital asset pricing model (CAPM) proposed by Fama and French $(1993,1996)$. Their augmented model argues that expected excess returns are related to 3 factors: (1) the market risk premium, (2) the difference in returns between a portfolio of small firm stocks and a portfolio of large firm stocks, and (3) the difference in returns between a portfolio of high book-to-market (BTM, a measure of value) stocks and a portfolio of low book-to-market stocks. However, an important stylised feature of performance that the model was unable to explain is the tendency for those stocks with momentum to experience continued abnormal performance in the short-term (Jegadeesh and Titman, 1993). This observation has led authors (notably Carhart, 1997, in a study of the abnormal performance of US mutual funds) to add a fourth factor to the model - momentum, that Carhart defined as the difference in returns between a portfolio of winner stocks and a portfolio of loser stocks, based on the past 12 months of returns.

A further potential but as yet unexplored source of variation in stock returns could arise from the presence of speculative bubbles. Entirely separate from that on asset pricing, a body of work has sought to explain the observed phenomenon that equity market prices often rise substantially, deviating a long way from values that appear economically justifiable, for prolonged periods. Such price dynamics at first blush seem inconsistent with the efficient markets hypothesis, but proponents of rational speculative bubble theory suggest that this price behaviour is entirely consistent with market rationality since investors are compensated for the increased risk of a price collapse by ever increasing returns. According to Santoni's (1987) definition, speculative bubbles have the special characteristic that they are persistent, systematic and increasing deviations of prices from their fundamental values. The fundamentals measure the underlying or intrinsic worth of an asset based on the suitably discounted stream of cash flows that will accrue to the holder.

Speculative bubbles are generated when investors include expectations of the future price of a security in their information set. Under these conditions, the actual market price of the 
asset will be a function of the expected future price and vice versa. In the presence of speculative bubbles, positive expected bubble returns will lead to increased demand and will thus force prices to diverge from their fundamental values. If the expectation of positive excess returns remains unchanged and the investor is compensated for the increased risk of bubble collapse, then these excess or abnormal returns will be realised in an increasing fashion. Thus, even though investors observe that stocks are overvalued, they are not willing to close out their positions because the bubble component offers at least the required rate of return. Prices increase slowly in the initial phase of the bubble, and then may grow exponentially before a collapse is eventually triggered as investors come to realise that the bubble-inflated price is unsustainable (see, for example, Kindleberger, 1989). Thus, as the riskiness of investing in the asset increases, so do the returns right until the point when the bubble bursts. Those who are holding the bubbly asset at this point will inevitably sustain heavy losses, but key to the formation of a bubble is that investors cannot predict precisely when it will collapse. All they can do, perhaps, is to estimate probabilistically the likelihood of collapse at any given point in time. If investors were able to forecast with precision when the bubble would collapse, the bubble would unravel back to its inception and could therefore never exist. It is important to note that, defined in this way, speculative bubbles can arise from entirely rational, forward-looking investor behaviour in the context of a limited information set, and could be thus considered consistent with orthodox asset pricing theory in the framework, for example, of Merton's (1973) intertemporal capital asset pricing model (ICAPM). The timing of the cycle of bubble inception, growth and collapse is clearly related to market sentiment and while the models that we employ in this paper do not require periodic irrational exuberance on the part of investors, such a characteristic would certainly encourage bubbly behaviour. ${ }^{1}$

The literature on testing for the presence of bubbles in stock markets alone is extensive (see, for example, Anderson et al., 2010; Brooks and Katsaris, 2003, 2005a, 2005b; Dezhbakhsh and Demirguc-Kunt; 1990; Donaldson and Kamstra, 1996, to name but a few), and the number of papers documenting bubble existence is considerably greater than those finding against. Pastor and Veronesi (2006), on the other hand, argue that the growth of

\footnotetext{
${ }^{1}$ Bustos, Andersen, Miniconi, Nowak, Roszczynska-Kurasinka and Brée (2011) present a suggestion on how sentiment can be incorporated in a model for stock prices.
} 
technology stock prices in the 1990s was not necessarily caused by a bubble. They demonstrate that firms' values grow with uncertainty about their future profitability. Even in the context of the simple Gordon growth model for dividends, when there is uncertainty about the future growth rate of dividends, the distribution of future dividends becomes right-skewed. So it is therefore rational for a technology stock to have a very high valuation relative to current earnings since the possibility that it will become hugely successful more than compensates for the likelihood that it will fail.

Do bubbles have any implications for asset pricing and the properties of stock returns, either theoretically or empirically? Several studies have tried to link, at least indirectly, the presence of asymmetries or anomalies in stock market returns, with the presence of speculative bubbles (see, for example, McQueen and Thorley, 1994 and Chen, Hong and Stein, 2001). Nevertheless, to our knowledge, there has been no research into the direct impact of bubbles on individual security returns or the cross-section of returns. Our study represents the first to empirically examine the impact that bubbles at the individual stock level may have on the market as a whole, and the extent to which bubble sizes can explain variations in stock returns.

The book-to-market equity and size factors have been rationalised as risk factors based on their ability to proxy for financial distress. Fama and French (1995) propose that firms with low price-to-book ratios may be in distress and have frequently suffered persistently low earnings. Indeed, Vassalou and Xing (2004) and Petkova (2006) show that the size and value factors both contain information related to financial distress and/or default risk, but these factors remain somewhat ad hoc and empirically motivated. A bubble factor, however, could proxy for risk more explicitly. From an intuitive perspective, it is easy to see why bubbles could be a priced risk factor. First, a corollary of the statement that an asset's price includes a (positive) speculative bubble is that it is trading at more than its underlying or intrinsic worth. In other words, relative to fundamentals, it is over-valued. Second, an asset whose price contains a speculative bubble is more likely, ceteris paribus, to experience a rapid and substantial fall in value, than an asset which does not. Thus, the fear of overpaying for assets and the fear that there will be a large and sudden price fall, tie in well with what many investors would consider as constituting risks. 
Several tests for the presence of speculative bubbles in financial markets have been developed in recent years. Such investigations include approaches based on variance bounds (see, for example, Shiller, 1981), tests for a bubble premium (Hardouvelis, 1988), tests based on cointegration analysis (Diba and Grossman, 1988), and tests based on regime switching models (van Norden, 1996). The latter of these approaches is a direct test for the presence of bubbles, whereas the former three are indirect tests that examine the distributional properties of prices and of fundamental measures. The weight of evidence has fallen strongly in favour of the presence of rational speculative bubbles. However, virtually all existing work has focused on the ex post identification of evidence for or against bubbles at the aggregate stock market-wide level and at the industry level (see Anderson et al., 2010). This implies that there is significant scope for research at the company-specific level. Such research may help towards an understanding of how bubbles are formed, and how they are priced by investors.

Our research has several overlapping objectives. First, we will apply the direct bubble tests as described above to individual stock price data in order to examine the extent to which bubbles are pervasive across equity markets. Several researchers have argued that speculative bubbles, or bubble-like behaviour, originate from high technology sectors, because the fundamental value of stocks within such high growth sectors is very difficult to estimate (Shiller, 2000, Hobijn and Jovanovic, 2001). Indeed, Cochrane (2003) argues that, "if there was a 'bubble,' or some behavioural overenthusiasm for stocks, it was concentrated on NASDAQ stocks, and NASDAQ tech and internet stocks in particular." Our investigation will shed some light on the validity or otherwise of such arguments.

Second, we will develop a new approach to determining the returns on risky assets by reference to a stock's exposure to "bubble risk". That is, we propose that individual stocks will have particular bubble sizes, and that those stocks with the largest bubbles will have the highest probability of bubble collapse and (ceteris paribus) will command the highest returns. Thus, an augmented Fama-French (1996) approach will be employed in order to test this conjecture. The first step will be to estimate the bubble sizes for each stock. The second will be to form equally weighted portfolios of large bubble stocks and of small bubble stocks, and the difference in average return between the large bubble and small bubble portfolios will be calculated. This measure will then be used in a time-series 
regression alongside the Fama-French plus momentum factors in order to determine whether bubble size is a priced common risk factor. This approach is based on Fama and French's variant of the original Black, Jensen and Scholes (1972) methodology. The universe of stocks will be formed into decile portfolios ranked (separately) according to beta, the book-to-market ratio, earnings-to-price, cash flow-to-price, and bubble size. The stocks will also be formed into 25 double-sorted portfolios by size and by book-to-market. In both cases, each of the portfolios will be subjected to the same time series regression so that the significances of the factors in each case can be compared.

Third, we demonstrate that the traditional CAPM beta can be decomposed into a fundamental beta and a bubble beta. This holds as long as we accept the definition that the bubble component of a stock should be independent both of its own and the market's fundamentals. We then perform second-stage Fama-MacBeth style regressions using these distinct components of beta.

The remainder of this paper is organised as follows. Section 2 describes our data and the methods that we employ in the paper to construct fundamental values. Section 3 presents our results from cross-sectional regressions, Section 4 covers how we determine the bubble factor loadings and the results therefrom, and Section 5 derives the decomposition into fundamental and CAPM betas and shows their results. Section 6 concludes and offers suggestions for further research.

\section{Data and Construction of Fundamentals}

\subsection{Data}

Thomson Reuters Datastream provides the most comprehensive dataset on UK companies and it is from this database that we draw the majority of the series used in this study. However, more complete information on a company's line of business is available from the London Share Price Database (LSPD, constructed at the London Business School). Also, information on which companies went into administration is only available from the LSPD. We therefore combined data from these two sources using the SEDOL code to match companies. The initial task was to arrive at a 'clean' list of UK companies for as long as the 
data allow. For a full list of companies that have data available on Datastream, we used the lists FBRIT for live companies and DEADUK for dead companies. We then excluded all companies with

- Company accounts, earnings or share price not quoted in GBP (allowing for differing currencies would complicate calculations unnecessarily)

- industry code G17 not available on the London Share Price Database (a few older, smaller companies have no code recorded)

- More than one type of share quoted (multiple classes of share would also complicate calculations unnecessarily).

We matched companies by SEDOL code across the two databases. Where no match was found using the SEDOL code, we carried out a manual name search. If necessary we also investigated changes of name using the Companies House WebCHeck service. This resulted in 1016 live companies from FBRIT and 3296 from DEADUK, giving 4312 in total over the period January 1980 to March 2012. ${ }^{2}$

Having arrived at a clean list of companies, we sourced monthly total return index data (including dividend payments and adjusted for stock splits, etc.) for each company from Datastream. Unfortunately, where a company goes into administration, its return index $(R /)$ often becomes stuck at the figure on its last traded day, and is not subsequently revised to zero. We therefore set the $R I$ to zero for all companies whose death reason according to the LSPD was 7 (liquidation), 14 (quotation cancelled for reasons unknown), 16 (receiver appointed / liquidation), 20 (in administration / administrative receivership) or 21 (cancelled, assumed valueless), starting in the month after the LSPD's death date. Finally, where the base $R I$ for month $m-1$ was not zero, we calculated the return for company $i$ in month $m$ in the standard fashion.

\footnotetext{
${ }^{2}$ Gregory et al. (2009) note that the number of firms listed on the main market of the London Stock Exchange has fallen from over 2000 in 1998 to half that number in 2008, although the number of firms on the Alternative Investment Market increased from around 300 to over 1500 during the same time period; our sample includes firms listed on both markets and thus the number of firms has been roughly stable over time.
} 
Book values are only available from January 1987 on Datastream, so all models using variables based on this start at that date. We took each company's book value per share and divided it by the share price to get the book value-to-price ratio. Fama and French (1992) allowed a six-month lag on the book values to be sure that all book values would have been publically available in the month of portfolio formation. We allowed a four-month lag however, since UK Listing Authority rules state that preliminary results must be released within 120 days of the company's year-end. Book value-to-price for company $i$ in month $m$ is then

$$
B V P_{i, m}=\frac{B V_{i, m-4}}{P_{i, m}}
$$

To calculate the Fama and French SMB (Small Minus Big) and HML (High Minus Low book value-to-price) factors, we allocated each company/month data item an $S$ or $B$ flag if was in the bottom or top $50 \%$ of stocks by market capitalisation, and a $H, M$ or $L$ flag if it was in the top $30 \%$, middle $40 \%$ or bottom $30 \%$ of stocks by book value to price in that month respectively. We then calculated average returns for each of the six combinations of these flags. The return figures for each portfolio are the average value-weighted excess returns for the stocks that fall into that group in that month. The average returns are the simple averages of the three small or large returns, or the two low or high returns. SMB for that month is then calculated as the value-weighted average return for all stocks in the small stock portfolio minus the value-weighted average return for all stocks in the large stock portfolio; $H M L$ is defined similarly. $R M R F$ is the average value-weighted return for that month of the stocks in the six cells in Table 1, plus companies with negative book values, minus the one-month Treasury bill rate.

For tests involving the Carhart four-factor model, we calculated the momentum figure for company $i$ in month $m$ following Carhart $(1997$, p.61) as the eleven-month momentum lagged one month:

$$
\operatorname{Mom}_{i, m}=\frac{R I_{i, m-1}-R I_{i, m-12}}{R I_{i, m-12}}
$$


To calculate UMD we allocated companies to low, medium or high momentum groups, using the bottom $30 \%$, middle $40 \%$ and top $30 \%$ of company momentums for that month. PR1YR for each month is then the value-weighted average one-month subsequent returns for the high momentum group, minus the returns for the low momentum group.

\subsection{Construction of Bubble Fundamentals}

Central to any model of bubble behaviour is how the fundamental value of the asset is estimated. Several methods can be found in the literature, but methods based on the Gordon Growth Model or dividend multiples are most popular. We use the dividend multiple method adopted by van Norden and Schaller (1999). It is widely appreciated that

the applicability of this method to high technology sectors such as biotechnology is questionable since many companies in these sectors do not currently pay dividends and may not plan to do so for many years, preferring to reward their investors with faster growing share prices. Damodaran (2000) nevertheless shows that the fundamentals of equity valuation apply to companies in such sectors just as validly as those elsewhere, although the valuations are often noisy. It would be possible to base the fundamental measure on earnings. However, as Keating et al. (2003) point out, during the "TMT bubble" growth period of the late 1990s, stock valuations were in many cases large multiples of sales, let alone profits. Indeed, stock prices continued to rise despite firms in some cases never having made a profit and therefore it is not clear that earnings would be a better measure of fundamentals than dividends. 'Soft' factors, sometimes considered as intangible assets, such as the evaluation of patents or web traffic for internet companies, could also play a part in any practical valuation, although Keating et al. (2003) find that they are no better than accounting information at explaining the cross-section of returns. Consequently, we do not use any of these highly subjective measures here and given that dividends represent the actual cash flows received by investors, we employ them as the basis of our fundamental measure while noting their limitations. One implication of this is that any stocks not paying dividends are excluded from the analysis - this is approximately $20 \%$ of the sample during the early 1980 s, rising to $40 \%$ towards the end of the period for which we have data. 
The proportion of stocks paying dividends has fallen over the years, and TMT stocks often do not pay dividends. Does this mean that our analysis will tend to exclude TMT stocks and thus be poor at identifying the technology stock bubble? We do not believe so. As can be seen from Figure 1, the percentage of dividend-paying stocks that are TMT stocks has been rising gently over the years, but there is no particular move during the 1995-2000 technology stock boom. Figure 1 also shows the percentage of TMT stocks in the low and high decile bubbles. The technology stock boom in the late 1990s saw TMT stocks move into the high bubble deciles at the expense of "old economy" stocks that were pushed into the low bubble deciles. Indeed the high bubble decile in the peak bubble month of March 2000 consisted of $65 \%$ TMT stocks. Thus we have clear evidence of the bubble's existence in the TMT sectors even though non-dividend bearing stocks were excluded from our sample.

Figure 1: Percentages of Dividend-Yielding Stocks that are TMT Stocks in Low Bubble and High Bubble Deciles and Across the Whole Sample

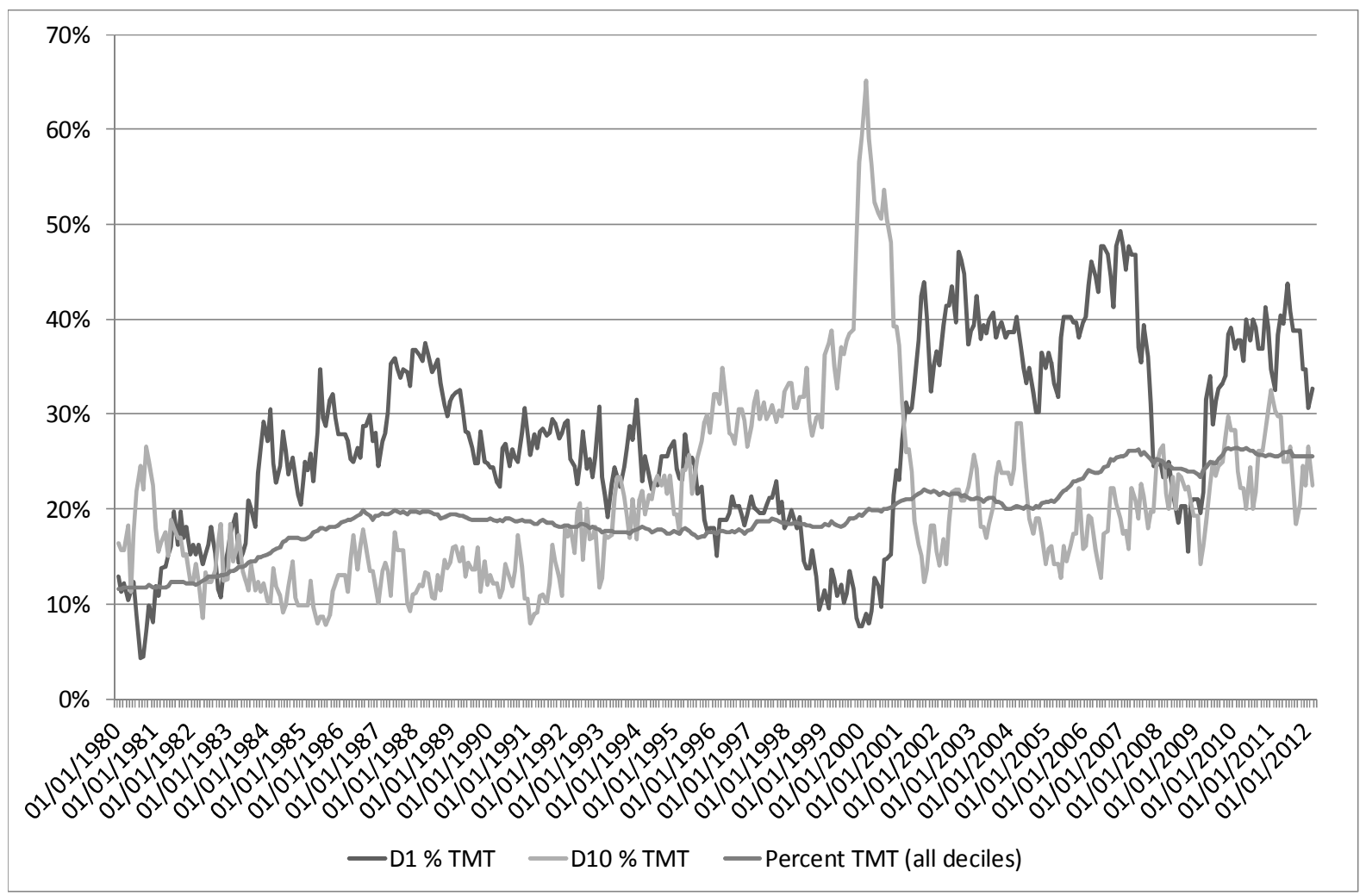

According to the discounted dividend model, the fundamental value of a stock $i$ is the present value of all of its future dividends: 
$p_{i, t}^{f}=\sum_{g=1}^{\infty} \frac{1}{(1+r)^{g}} E_{t}\left(d_{i, t+g}\right)$

where $p_{i, t}^{f}$ is the fundamental price of stock $i$ at time $t, d_{i, t}$ is the dividend stock $i$ paid in period $t, r$ is the market discount rate (the required rate of return, which is assumed constant), and $E_{t}($.$) is the expectations operator conditioning on information available at$ time $t$. If the actual price of the stock, $p_{i, t}{ }^{a}$, contains a bubble, then it will follow the dynamic process:

$p_{i, t}^{a}=p_{i, t}^{f}+b_{i, t}+u_{i, t}$

where $b_{i, t}$ is the bubble component, and $u_{i, t}$ is a zero mean, random disturbance term.

van Norden and Schaller (1999), vNS hereafter, show that, if dividends follow a geometric random walk (i.e. log dividends follow a random walk with drift $a$ ), and given a constant discount rate, then the fundamental value of a stock must be a multiple of current dividends:

$p_{i, t}^{f}=\rho d_{i, t}$

Using a second order Taylor series expansion, vNS show that the fundamental price of company $i$ at time $t$ can be approximated by a multiple $\rho$ of the dividends the company paid then, where $\rho=\frac{1+r}{e^{\left(a+\frac{\sigma^{2}}{2}\right)}-1}, r$ is the subjective discount rate, and $\sigma^{2}$ is the variance of the innovations in the random walk with drift process for dividends.

Following vNS, our approximation of the value of $\rho$ is to use a trailing average of the pricedividend ratio, in our case calculated over the previous five years. The relative bubble size relative to the actual price is then:

$B_{i, t}=\frac{b_{i, t}}{p_{i, t}}=\frac{p_{i, t}-p_{i, t}^{f}}{p_{i, t}}=1-\frac{\rho d_{i, t}}{p_{i, t}}$

In other words, our estimate of the relative bubble size for company $i$ at time $t$ is the proportional deviation from the fundamental price of the actual observed price. Thus, for example, if the dividend yield for the whole sample is $5 \%$ (price - dividend ratio $=20$ ), and 
this company is currently priced at $f 1$ but only paying a $2 p$ dividend, we estimate the relative bubble size as $60 \%$ :

$B_{i, t}=1-\frac{\rho d_{i, t}}{p_{i, t}}=1-\frac{20 \times 2}{100}=0.6$

Large negative bubble values are more difficult to understand intuitively. What is the meaning of a bubble deviation of, say, $-900 \%$ ? Taking the above example, with the dividend yield for the whole sample still at $5 \%$ and the stock priced at $£ 1$ :

$$
\begin{aligned}
& B_{i, t}=1-\frac{\rho d_{i, t}}{p_{i, t}} \\
& -9=1-\frac{20 d_{i, t}}{100} \\
& -10=-\frac{20 d_{i, t}}{100} \\
& d_{i, t}=\frac{1000}{20}=50
\end{aligned}
$$

So in this extreme case, a stock priced at $£ 1$ is paying a $50 p$ dividend (or, at least, did last year) and is thus offering ten times the market average dividend yield.

Some summary statistics for the bubble deviations, expressed as percentages of the actual stock prices, are presented in Table 1, averaged within each year for presentational ease. 
Table 1: Summary Statistics for Bubble Deviations by Year

\begin{tabular}{|c|c|c|c|c|c|c|c|c|c|}
\hline Year & Mean & $\begin{array}{l}\text { Standard } \\
\text { Deviation }\end{array}$ & Minimum & $\begin{array}{c}10^{\text {th }} \\
\text { Percentile }\end{array}$ & $\begin{array}{c}25^{\text {th }} \\
\text { Percentile }\end{array}$ & Median & $\begin{array}{c}75^{\text {th }} \\
\text { Percentile }\end{array}$ & $\begin{array}{c}90^{\text {th }} \\
\text { Percentile }\end{array}$ & Maximum \\
\hline 1980 & $-4.91 \%$ & $19.93 \%$ & $-232.48 \%$ & $-22.88 \%$ & $-11.68 \%$ & $-2.98 \%$ & $4.71 \%$ & $12.07 \%$ & $64.97 \%$ \\
\hline 1981 & $-8.38 \%$ & $439.94 \%$ & $-12079.94 \%$ & $-26.78 \%$ & $-10.30 \%$ & $3.90 \%$ & $17.77 \%$ & $32.41 \%$ & $90.25 \%$ \\
\hline 1982 & $-5.99 \%$ & $246.53 \%$ & $-7588.37 \%$ & $-33.60 \%$ & $-10.46 \%$ & $6.12 \%$ & $21.16 \%$ & $38.00 \%$ & $90.33 \%$ \\
\hline 1983 & $0.61 \%$ & $151.85 \%$ & $-3498.42 \%$ & $-28.83 \%$ & $-4.81 \%$ & $12.21 \%$ & $27.62 \%$ & $45.51 \%$ & $93.25 \%$ \\
\hline 1984 & $-7.59 \%$ & $184.08 \%$ & $-3649.67 \%$ & $-37.52 \%$ & $-8.52 \%$ & $9.62 \%$ & $25.50 \%$ & $41.09 \%$ & $89.25 \%$ \\
\hline 1985 & $-31.12 \%$ & $411.01 \%$ & $-11363.55 \%$ & $-60.74 \%$ & $-16.62 \%$ & $5.11 \%$ & $22.75 \%$ & $39.43 \%$ & $89.83 \%$ \\
\hline 1986 & $-24.62 \%$ & $301.36 \%$ & $-6892.49 \%$ & $-61.15 \%$ & $-12.25 \%$ & $8.89 \%$ & $26.69 \%$ & $41.53 \%$ & $90.26 \%$ \\
\hline 1987 & $3.53 \%$ & $153.81 \%$ & $-3729.28 \%$ & $-29.16 \%$ & $-2.18 \%$ & $18.43 \%$ & $34.76 \%$ & $48.82 \%$ & $85.90 \%$ \\
\hline 1988 & $-20.62 \%$ & $111.97 \%$ & $-2493.89 \%$ & $-71.88 \%$ & $-29.31 \%$ & $-1.98 \%$ & $15.21 \%$ & $31.01 \%$ & $85.80 \%$ \\
\hline 1989 & $-39.60 \%$ & $357.22 \%$ & $-11774.64 \%$ & $-97.38 \%$ & $-42.12 \%$ & $-9.85 \%$ & $8.26 \%$ & $23.53 \%$ & $88.03 \%$ \\
\hline 1990 & $-101.62 \%$ & $552.70 \%$ & $-15064.06 \%$ & $-197.21 \%$ & $-100.86 \%$ & $-47.15 \%$ & $-16.70 \%$ & $2.98 \%$ & $88.62 \%$ \\
\hline 1991 & $-118.37 \%$ & $2156.15 \%$ & $-32200.14 \%$ & $-202.92 \%$ & $-102.17 \%$ & $-44.12 \%$ & $-13.11 \%$ & $7.94 \%$ & $89.05 \%$ \\
\hline 1992 & $-64.87 \%$ & $190.58 \%$ & $-3269.05 \%$ & $-159.85 \%$ & $-72.10 \%$ & $-24.62 \%$ & $2.13 \%$ & $18.81 \%$ & $89.76 \%$ \\
\hline 1993 & $-7.86 \%$ & $87.61 \%$ & $-1394.73 \%$ & $-60.59 \%$ & $-16.88 \%$ & $7.87 \%$ & $25.97 \%$ & $41.55 \%$ & $89.98 \%$ \\
\hline 1994 & $2.44 \%$ & $117.81 \%$ & $-2953.71 \%$ & $-35.57 \%$ & $-3.22 \%$ & $15.70 \%$ & $32.82 \%$ & $47.03 \%$ & $92.28 \%$ \\
\hline 1995 & $-23.16 \%$ & $281.18 \%$ & $-7010.65 \%$ & $-60.29 \%$ & $-20.50 \%$ & $1.70 \%$ & $18.73 \%$ & $33.83 \%$ & $86.82 \%$ \\
\hline 1996 & $-26.51 \%$ & $242.15 \%$ & $-6385.09 \%$ & $-70.42 \%$ & $-28.16 \%$ & $-2.55 \%$ & $16.11 \%$ & $33.43 \%$ & $90.47 \%$ \\
\hline 1997 & $-46.70 \%$ & $342.38 \%$ & $-8280.74 \%$ & $-104.45 \%$ & $-47.07 \%$ & $-11.64 \%$ & $8.61 \%$ & $26.25 \%$ & $84.04 \%$ \\
\hline 1998 & $-79.32 \%$ & $529.82 \%$ & $-13870.10 \%$ & $-149.45 \%$ & $-74.91 \%$ & $-25.62 \%$ & $2.73 \%$ & $24.84 \%$ & $80.79 \%$ \\
\hline 1999 & $-68.06 \%$ & $422.55 \%$ & $-9338.57 \%$ & $-142.75 \%$ & $-68.14 \%$ & $-19.68 \%$ & $9.00 \%$ & $31.30 \%$ & $85.92 \%$ \\
\hline 2000 & $-51.11 \%$ & $384.88 \%$ & $-9796.09 \%$ & $-118.17 \%$ & $-56.11 \%$ & $-14.64 \%$ & $16.80 \%$ & $42.05 \%$ & $88.20 \%$ \\
\hline 2001 & $-64.90 \%$ & $302.63 \%$ & $-6373.69 \%$ & $-151.37 \%$ & $-62.99 \%$ & $-19.95 \%$ & $6.03 \%$ & $25.91 \%$ & $82.19 \%$ \\
\hline 2002 & $-78.55 \%$ & $361.17 \%$ & $-6064.59 \%$ & $-165.10 \%$ & $-67.65 \%$ & $-20.19 \%$ & $4.93 \%$ & $25.08 \%$ & $80.86 \%$ \\
\hline 2003 & $-73.76 \%$ & $255.57 \%$ & $-3553.80 \%$ & $-177.21 \%$ & $-74.31 \%$ & $-18.60 \%$ & $6.13 \%$ & $26.57 \%$ & $82.60 \%$ \\
\hline 2004 & $-27.43 \%$ & $182.01 \%$ & $-2934.79 \%$ & $-93.51 \%$ & $-26.07 \%$ & $3.68 \%$ & $22.74 \%$ & $38.86 \%$ & $78.93 \%$ \\
\hline 2005 & $-17.07 \%$ & $169.89 \%$ & $-3398.23 \%$ & $-76.75 \%$ & $-21.19 \%$ & $6.87 \%$ & $25.72 \%$ & $37.41 \%$ & $85.56 \%$ \\
\hline 2006 & $-15.75 \%$ & $95.12 \%$ & $-1282.31 \%$ & $-80.03 \%$ & $-26.90 \%$ & $4.08 \%$ & $24.71 \%$ & $38.16 \%$ & $82.28 \%$ \\
\hline 2007 & $-18.17 \%$ & $89.05 \%$ & $-1229.14 \%$ & $-81.31 \%$ & $-31.92 \%$ & $-0.08 \%$ & $21.35 \%$ & $37.21 \%$ & $75.17 \%$ \\
\hline 2008 & $-43.15 \%$ & $244.54 \%$ & $-3981.69 \%$ & $-118.39 \%$ & $-45.35 \%$ & $-7.03 \%$ & $15.72 \%$ & $32.97 \%$ & $81.15 \%$ \\
\hline 2009 & $-165.80 \%$ & $552.01 \%$ & $-10481.68 \%$ & $-313.35 \%$ & $-152.99 \%$ & $-78.82 \%$ & $-30.91 \%$ & $-1.14 \%$ & $67.57 \%$ \\
\hline 2010 & $-63.30 \%$ & $340.74 \%$ & $-6752.93 \%$ & $-134.08 \%$ & $-66.23 \%$ & $-23.87 \%$ & $3.22 \%$ & $27.75 \%$ & $78.96 \%$ \\
\hline 2011 & $-38.60 \%$ & $229.08 \%$ & $-4115.86 \%$ & $-94.52 \%$ & $-42.43 \%$ & $-8.28 \%$ & $14.55 \%$ & $33.02 \%$ & $81.69 \%$ \\
\hline 2012 & $-46.37 \%$ & $295.07 \%$ & $-5113.05 \%$ & $-102.01 \%$ & $-43.86 \%$ & $-9.05 \%$ & $13.59 \%$ & $32.00 \%$ & $84.66 \%$ \\
\hline
\end{tabular}

Notes: The bubble deviations are defined as the bubble size (difference between actual prices and their fundamental values, based on dividend payments as in Section 2.1) expressed as a proportion of the actual share price at that time. The bubble deviations are constructed using five-year windows to evaluate the long term price-to-dividend ratios, rolled forward on a monthly basis. The figures for each year are averages of all months in that year (the 2012 figure only averages over January - March).

Given our method of constructing fundamentals using equation (4), the bubble deviation will effectively fall as the firm increases its dividend payment relative to its historical average. A firm with a large price to dividend ratio (i.e. one that has historically had a small dividend payout ratio and so has a large $\rho$ but which substantially increases its dividend) could have a very negative bubble deviation. For example, suppose the dividend yield for the past five 
years is now $1 \%$ (price - dividend ratio $=100$ ), and this company is currently priced at $f 1$ but paying a $10 \mathrm{p}$ dividend, $B_{i, t}$, the bubble deviation, will be $-900 \%$. On the other hand, $B_{i, t}$ will approach $100 \%$ as the firm reduces its dividend payment relative to its historical value.

It should be apparent that the bubble deviations are bounded from above by $100 \%$ (if the entire stock price comprises a bubble and the fundamental value is zero) but they are not bounded from below and consequently the distribution of bubble deviations has a very long lower tail and is skewed. As a result, the mean bubble deviation is negative in most years, and the median deviation, shown in column seven of Table 1, is arguably a better summary statistic. Even the median stock has a negative bubble deviation for over half of the sample years, perhaps in part reflecting the declining propensity over time of firms to pay dividends. This should be inconsequential for our models below, however, since the stocks are compared cross-sectionally within each year separately and thus the rank ordering of bubble deviations is key rather than their absolute magnitudes.

The profile of the relative bubble sizes over time is as one would expect, reaching peaks in 1983, 1987, 1994 and 2005, before subsequent market crashes deflated the bubbles that had established. Stocks were at their most undervalued, when more than half traded at below their fundamental values, during 1988-1991, 1997-2003, and 2008 onwards. The years towards the end of our sample period, especially in 2009, are particularly interesting. Unlike the bubble collapses of late 1987 and 1998-2000, prices as a multiple of dividends were not at historically unprecedented levels in 2009. During the mid-2000s, dividend payments had been increasing at a considerable rate. Clearly, a small number of stocks were very over-valued, trading at up to ten times their fundamental values.

To further investigate the relationship between the cross-sectional variation in the bubble sizes and the stock market, Figure 2 plots the bubble deciles over time against the value of the FTSE All-Shares Index. It is apparent that the tenth percentile of the bubble deviation distribution has the ability to identify buying opportunities, spiking before the run-ups in 1991, 2003 and 2009. The ninetieth percentile identified appropriate points to sell in 1987 and 2000; however, if this series were used to define an investment rule, it would have 
given a false signal in 1994 and any investor following this would have missed out on the upside over the next six years. ${ }^{3}$

Figure 2: Bubble Percentiles versus FTSE All-Share Index Returns Over Time

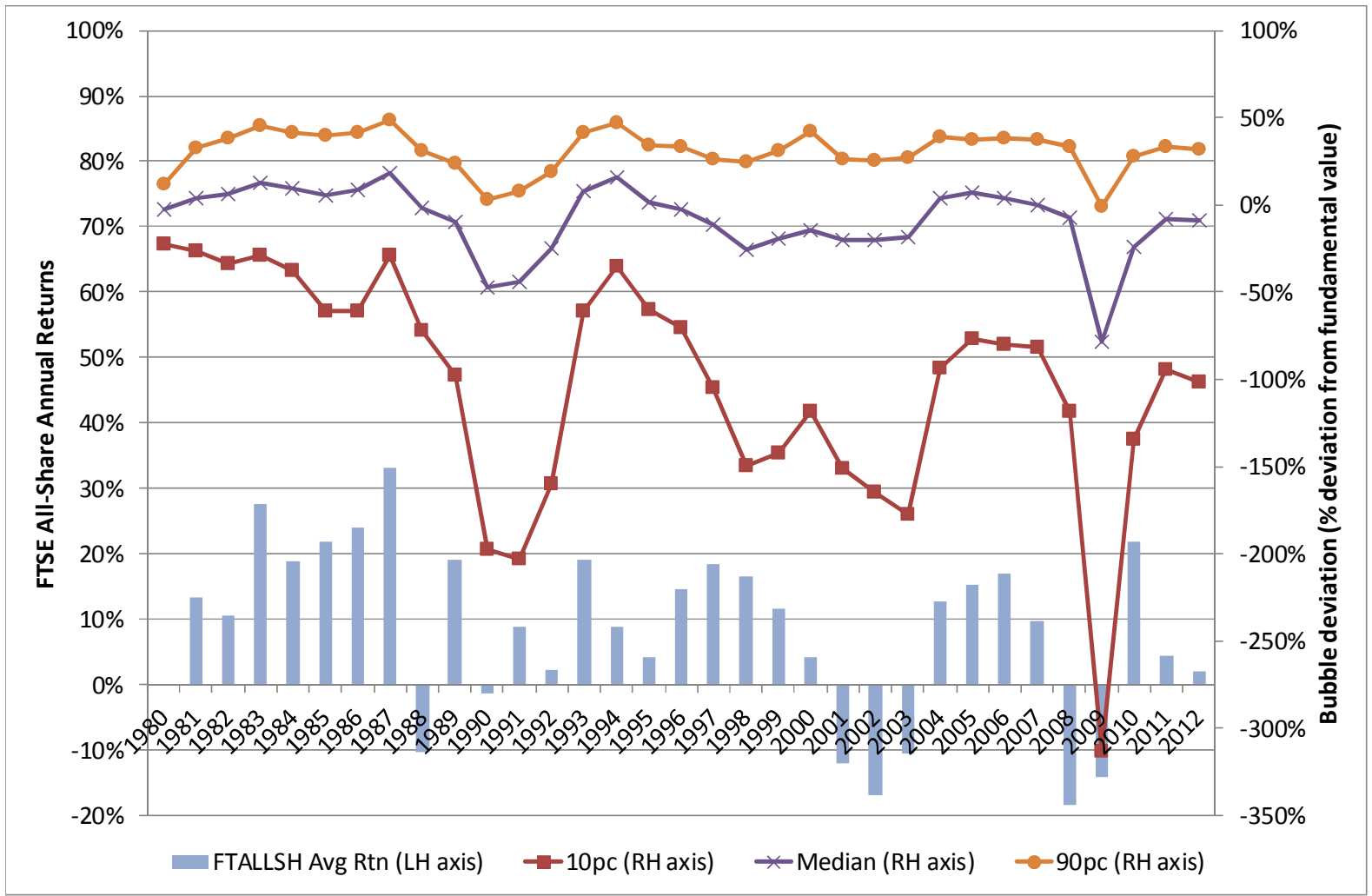

\section{Cross-Sectional Regressions}

\section{1: Cross-Sectional Regressions to Determine Whether Bubbles Affect Returns}

We first use the Fama-French (1992) approach based on a "time-series of cross-sections" with an additional variable representing the size of the bubble deviations using the following procedure. We run a cross-sectional regression of the form

$$
R_{i, t}=\alpha+\beta_{1} \operatorname{Beta}_{i, t}+\beta_{2} M V_{i, t}+\beta_{3} B V P_{i, t}+\beta_{4} M O M_{i, t}+\beta_{5} D Y_{i t}+\beta_{6} B_{i, t}+u_{i, t}
$$

where $R$ are the monthly returns, ${ }^{4}$ Beta are the CAPM betas calculated as the slope of a regression of log monthly returns over the previous five years against those of the FTSE All

\footnotetext{
${ }^{3}$ It might be possible to develop the bubble deciles, or the differences between them, into an effective market timing rule in a more sophisticated version of that in Brooks and Katsaris (2005b). However, this is not the focus of the present paper and thus we do not pursue this idea further.
} 
Share Index (provided that at least 24 months of returns are available), $M V$ are the market capitalisations, BVP is the book-to-price ratio, MOM is the previous year's return for the stock to measure the extent to which it has momentum, $D Y$ is the dividend yield, $B$ is the bubble deviation as a percentage of the actual price, as described above, and the subscripts denote firm $i$ and month $t^{5}$

We checked the correlations of the variables in equation (7) month-by-month. The correlations averaged across all months ranged between -0.34 and +0.29 ; no correlation in any individual month exceeded \pm 0.66 . Multicollinearity should not therefore be a problem.

\subsection{Results from the Models Incorporating Bubble Deviations Directly}

The results from the cross-sectional regression of monthly returns on the firm-specific characteristics are presented in Table 2 for three separate sub-samples. The first panel presents the results for the whole sample from May 1980 to March 2012, and the second two panels present results for the shorter sub-samples January 1990 to March 2012 and January 2000 - March 2012. We choose the first of these sub-samples in order to remove any "burn in" effect from having insufficient prior observations to estimate the long term price-to-dividend ratio in the whole sample, and the second sub-sample allows us to focus on the post-technology bubble bursting period only.

Several specifications are examined in each case. The first is a simple test of the CAPM, and shows that the coefficient on beta is never statistically significantly different from zero and sometimes has the wrong sign. The bubble term, on the other hand, is significant at the $1 \%$ level in every model. When the market capitalisation, book-value-to-price, and momentum terms are incorporated, neither the bubble term's magnitude nor its statistical significance

\footnotetext{
${ }^{4}$ The regression in (7) could be conducted using actual returns or excess returns as the dependent variable (i.e. with a proxy for the risk-free rate of interest subtracted) and for comparison we also employed the latter. However, we retain the former in the results shown in Tables 2 and 6.

${ }^{5}$ The cross-section of market capitalisation is heavily skewed, with a few extremely large companies in the sample. We thus repeat the analysis using the natural logarithm of MV rather than its level. However, the findings are not qualitatively affected and we thus do not report the results for the logs. The distribution of bubble deviations is similarly skewed, as discussed in the text; again, as a robustness check we repeat the analysis using the deciles to which the bubble deviations belong rather than their actual values in equation (6). We find that the results are stronger, in the sense that the coefficients on the bubble term are still positive but more statistically significant and the $\mathrm{R}^{2}$ rises. However, we prefer to report the results with the actual bubble deviations since these have a more natural interpretation.
} 
are more than modestly affected. However the momentum coefficient in Panel A of Table 2 changes from positive and highly significant under the Carhart (1997) model, to negative with $5 \%$ significance when the bubble term is added, to negative and highly significant when dividend yield is added. It seems that the bubble term dominates the momentum term, and in addition we should note that the sample for the models including a dividend yield and including the bubble term are smaller cross-sectionally than those without and therefore the results for the models with and without the bubble term are not strictly comparable. ${ }^{6}$

The final row in each panel incorporates the firm's current dividend yield in the specification to tackle potential concerns that the bubble factor may simply be another way of picking this up; it has been widely documented in the empirical asset pricing literature that high yielding stocks generate higher returns on average (see, for example, Hodrick, 1992; Kothari and Shanken, 1997). It is clear from Table 2 that the inclusion of dividend yield does not reduce the impact of the bubble on the cross-section of returns. A parameter estimate of 1.66 on the bubble factor in the most complete specification for the whole sample period implies that a $10 \%$ increase in the bubble deviation as a fraction of the actual price would lead to a $0.166 \%$ increase in average returns per month (approximately $2 \%$ per annum). It should be noted that the coefficients of determination presented in this table, while modest in size, are in accord with those of other cross-sectional stock return regressions in the extant literature. We should note at this stage the small $R^{2}$ values in these regressions (although such values are not uncommon in the literature) and that the increase in explanatory power from the bubble terms is modest and from a low base.

\footnotetext{
${ }^{6}$ It would of course be possible to run all models on the same cross-sectional sample of firms throughout that pay dividends. However, we prefer to retain as many observations as possible for each individual regression.
} 
Table 2: Time-series of Cross-section Results for CAPM and Fama-French Specifications including a Bubble Term

\begin{tabular}{|c|c|c|c|c|c|c|c|c|}
\hline \multicolumn{9}{|c|}{ Panel A: Whole Sample May 1980 - March 2012 (383 points) } \\
\hline Intercept & Beta & Size & BVP & Mom & DY & Bubble & $\mathbf{R}^{2}$ & \# obs \\
\hline $\begin{array}{l}1.118 \\
(0.162)^{* * *}\end{array}$ & $\begin{array}{l}-0.001 \\
(0.273)\end{array}$ & - & - & - & - & - & 0.04 & 1143 \\
\hline $\begin{array}{l}1.467 \\
(0.235)^{* * *}\end{array}$ & - & - & - & - & - & $\begin{array}{l}1.312 \\
(0.241)^{* * *}\end{array}$ & 0.02 & 907 \\
\hline $\begin{array}{l}1.458 \\
(0.142)^{* * *}\end{array}$ & $\begin{array}{l}0.014 \\
(0.275)\end{array}$ & - & - & - & - & $\begin{array}{l}1.467 \\
(0.241)^{* * *}\end{array}$ & 0.06 & 823 \\
\hline $\begin{array}{l}0.801 \\
(0.253)^{* * *}\end{array}$ & $\begin{array}{l}0.032 \\
(0.276)\end{array}$ & $\begin{array}{l}0.00003 \\
(0.00003)\end{array}$ & $\begin{array}{l}-0.354 \\
(0.032)^{* * *}\end{array}$ & $\begin{array}{l}0.559 \\
(0.165)^{* * *}\end{array}$ & - & - & 0.06 & 779 \\
\hline $\begin{array}{l}2.461 \\
(0.284)^{* * *}\end{array}$ & $\begin{array}{l}-0.030 \\
(0.281)\end{array}$ & $\begin{array}{l}0.00002 \\
(0.0003)\end{array}$ & $\begin{array}{l}-0.878 \\
(0.061)^{* * *}\end{array}$ & $\begin{array}{l}-0.390 \\
(0.211)^{*}\end{array}$ & - & $\begin{array}{l}1.868 \\
(0.226)^{* * *}\end{array}$ & 0.10 & 576 \\
\hline $\begin{array}{l}4.890 \\
(0.274)^{* * *}\end{array}$ & $\begin{array}{l}-0.113 \\
(0.279)\end{array}$ & $\begin{array}{l}0.00002 \\
(0.00003)\end{array}$ & $\begin{array}{l}-0.635 \\
(0.054)^{* * *}\end{array}$ & $\begin{array}{l}-1.143 \\
(0.202)^{* * *}\end{array}$ & $\begin{array}{l}-0.415 \\
(0.022)^{* * *}\end{array}$ & $\begin{array}{l}1.659 \\
(0.215)^{* * *}\end{array}$ & 0.11 & 576 \\
\hline \multicolumn{9}{|c|}{ Panel B: Sub-sample January 1990 - March 2012 (267 points) } \\
\hline Intercept & Beta & Size & BVP & Mom & DY & Bubble & $\mathbf{R}^{2}$ & \# obs \\
\hline $\begin{array}{l}0.637 \\
(0.196)^{* * *}\end{array}$ & $\begin{array}{l}0.005 \\
(0.325)\end{array}$ & - & - & - & - & - & 0.04 & 1143 \\
\hline $\begin{array}{l}1.144 \\
(0.275)^{* * *}\end{array}$ & - & - & - & - & - & $\begin{array}{l}0.664 \\
(0.057)^{* * *}\end{array}$ & 0.02 & 810 \\
\hline $\begin{array}{l}1.118 \\
(0.169)^{* * *}\end{array}$ & $\begin{array}{l}0.038 \\
(0.332)\end{array}$ & - & - & - & - & $\begin{array}{l}0.631 \\
(0.056)^{* * *}\end{array}$ & 0.06 & 751 \\
\hline $\begin{array}{l}0.616 \\
(0.322)^{*}\end{array}$ & $\begin{array}{l}0.050 \\
(0.325)\end{array}$ & $\begin{array}{l}0.00003 \\
(0.00002)\end{array}$ & $\begin{array}{l}-0.451 \\
(0.040)^{* * *}\end{array}$ & $\begin{array}{l}0.378 \\
(0.214)^{*}\end{array}$ & - & & 0.06 & 943 \\
\hline $\begin{array}{l}2.654 \\
(0.373)^{* * *}\end{array}$ & $\begin{array}{l}0.052 \\
(0.340)\end{array}$ & $\begin{array}{l}0.00001 \\
(0.00002)\end{array}$ & $\begin{array}{l}-1.225 \\
(0.076)^{* * *}\end{array}$ & $\begin{array}{l}-0.697 \\
(0.283)^{* *}\end{array}$ & - & $\begin{array}{l}0.985 \\
(0.074)^{* * *}\end{array}$ & 0.10 & 661 \\
\hline $\begin{array}{l}4.982 \\
(0.347)^{* * *}\end{array}$ & $\begin{array}{l}0.017 \\
(0.338)\end{array}$ & $\begin{array}{l}0.00001 \\
(0.00002)\end{array}$ & $\begin{array}{l}-0.891 \\
(0.071)^{* * *}\end{array}$ & $\begin{array}{l}-1.519 \\
(0.271)^{* * *}\end{array}$ & $\begin{array}{l}-0.413 \\
(0.024)^{* * *}\end{array}$ & $\begin{array}{l}0.797 \\
(0.068) * * *\end{array}$ & 0.11 & 661 \\
\hline \multicolumn{9}{|c|}{ Panel C: Sub-sample January 2000 - March 2012 (147 points) } \\
\hline Intercept & Beta & Size & BVP & Mom & DY & Bubble & $\mathbf{R}^{2}$ & \# obs \\
\hline $\begin{array}{l}0.577 \\
(0.282)^{* *}\end{array}$ & $\begin{array}{l}-0.221 \\
(0.431)\end{array}$ & - & - & - & - & - & 0.04 & 1145 \\
\hline $\begin{array}{l}1.108 \\
(0.389)^{* * *}\end{array}$ & - & - & - & - & - & $\begin{array}{l}0.750 \\
(0.088)^{* * *}\end{array}$ & 0.03 & 617 \\
\hline 1.260 & -0.184 & - & - & - & - & 0.711 & 0.08 & 589 \\
\hline$(0.219)^{* * *}$ & $(0.450)$ & & & & & $(0.087)^{* * *}$ & & \\
\hline 1.304 & -0.217 & 0.000004 & -0.519 & -0.180 & - & - & 0.06 & 943 \\
\hline$(0.468)^{* * *}$ & $(0.438)$ & $(0.00001)$ & $(0.061)^{* * *}$ & $(0.332)$ & & & & \\
\hline $\begin{array}{l}4.091 \\
(0.549)^{* * *}\end{array}$ & $\begin{array}{l}-0.278 \\
(0.478)\end{array}$ & $\begin{array}{l}-0.00001 \\
(0.00001)^{*}\end{array}$ & $\begin{array}{l}-1.499 \\
(0.108)^{* * *}\end{array}$ & $\begin{array}{l}-1.613 \\
(0.453)^{* * *}\end{array}$ & - & $\begin{array}{l}1.195 \\
(0.114)^{* * *}\end{array}$ & 0.11 & 524 \\
\hline $\begin{array}{l}5.416 \\
(0.533)^{* * *}\end{array}$ & $\begin{array}{l}-0.399 \\
(0.475)\end{array}$ & $\begin{array}{l}-0.00001 \\
(0.00001)^{*}\end{array}$ & $\begin{array}{l}-1.236 \\
(0.107)^{* * *}\end{array}$ & $\begin{array}{l}-1.970 \\
(0.443)^{* * *}\end{array}$ & $\begin{array}{l}-0.303 \\
(0.035)^{* * *}\end{array}$ & $\begin{array}{l}1.034 \\
(0.107)^{* * *}\end{array}$ & 0.13 & 524 \\
\hline
\end{tabular}

Notes: in the full model we run a series of cross-sectional regressions of the form

$R_{i, t}=\alpha+\beta_{1}$ Beta $_{i, t}+\beta_{2} M V_{i, t}+\beta_{3} B V P_{i, t}+\beta_{4} M O M_{i, t}+\beta_{5} D Y_{i t}+\beta_{6} B_{i, t}+u_{i, t}$

where $R$ are the monthly returns, Beta are the CAPM betas calculated as the slope of a regression of log monthly returns over the previous five years against those of the FTSE All Share Index (provided that at least 24 months of returns are available), $M V$ are the market capitalisations, $B V P$ is the book-to-price ratio, MOM is the previous year's return for the stock to measure the extent to which it has momentum, $D Y$ is the dividend yield, $B$ is the bubble deviation as a percentage of the actual price, and the subscripts denote firm $i$ and month $t$. The $\mathrm{R}^{2}$ and \# obs (number of observations) are the averages over all of the cross-sectional regressions for a given specification. 


\section{Bubble Factor Loadings}

\subsection{Determining the Bubble Factor Loadings and the Risk Premia}

In the spirit of Fama and French (1993), we construct a bubble factor where we sort stocks by their bubble deviations into triciles based on the top $30 \%$, the bottom $30 \%$ and the remaining $40 \%$ in the middle. The bubble factor $B B M S B_{t}$ ("big bubble minus small bubble") is then formed by subtracting the returns on the portfolio of stocks with the smallest bubble deviations from the returns of the portfolio of stocks with the largest bubble deviations. We assume that the bubble-based portfolios are reformed monthly and are value-weighted.

For illustration, the stocks are also sorted into deciles (rather than triciles) based on the sizes of their bubble deviations, and their characteristics are shown in Table 3. The first two rows report the returns on each portfolio when it is equally weighted (first row after the header) and value weighted (second row). It is clearly evident that there is a positive bubble premium in the sense that stocks within the largest bubble decile generate returns of $4.78 \%$ per annum (3.61\% value weighted) whereas those in the lowest bubble decile produce negative returns $(-2.87 \%$ or $-2.35 \%$ value weighted); thus a zero cost strategy of buying the $10 \%$ of stocks with the largest bubbles and short selling the $10 \%$ of stocks with the smallest bubble deviations would yield a profit of $7.66 \%$ (5.96\% if value-weighted). The third row of the table shows the average size of the company in each bubble-sorted decile by the percentile rank (so low numbers denote the smallest companies). This shows that, aside from the companies with the smallest bubble deviations, which tend to be smaller companies, there is little to choose between the rest, indicating very little association between firm size and bubble size. Similarly, aside from the decile of smallest bubble deviation companies having the highest betas, there is very little separation between the rest, so that bubble size and market risk are otherwise uncorrelated. The table also shows that, perhaps as one would expect, bubble companies tend to be growth stocks with low book-to-market ratios, and in particular the decile with the smallest bubbles have book-tomarket ratios around $40 \%$ higher than those in the decile with the largest bubbles. 
Table 3: Returns and Other Characteristics for Portfolios formed on Bubble Size

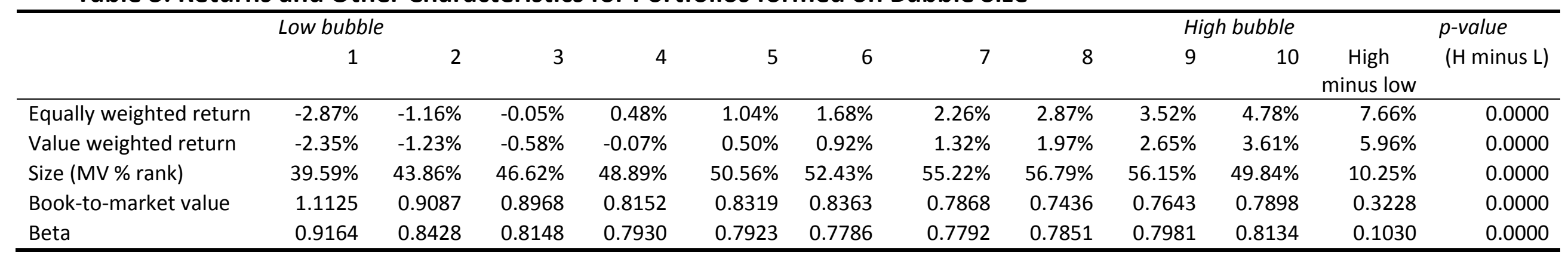

Notes: The table presents percentage annualised returns and other characteristics calculated on the basis of ranking stocks by the sizes of their bubble deviations and then allocating them to decile portfolios. The figures are the simple averages of the monthly values. 
To illustrate the difference in returns, Figure 3 shows how three equally-weighted bubble decile portfolios fared over the years, starting with $f 1,000$ in 1980 and rebalancing annually. The highest bubble decile D10 performs the best, but suffers markedly more in market downturns. Its $-11 \%$ return from $01 / 03 / 2000$ to $01 / 03 / 2001$ contributes to its total value falling below that of the decile 5 portfolio in 2002 and 2003.

Figure 3: Portfolio Returns for the High, Middle and Low Bubble Deciles Across Time

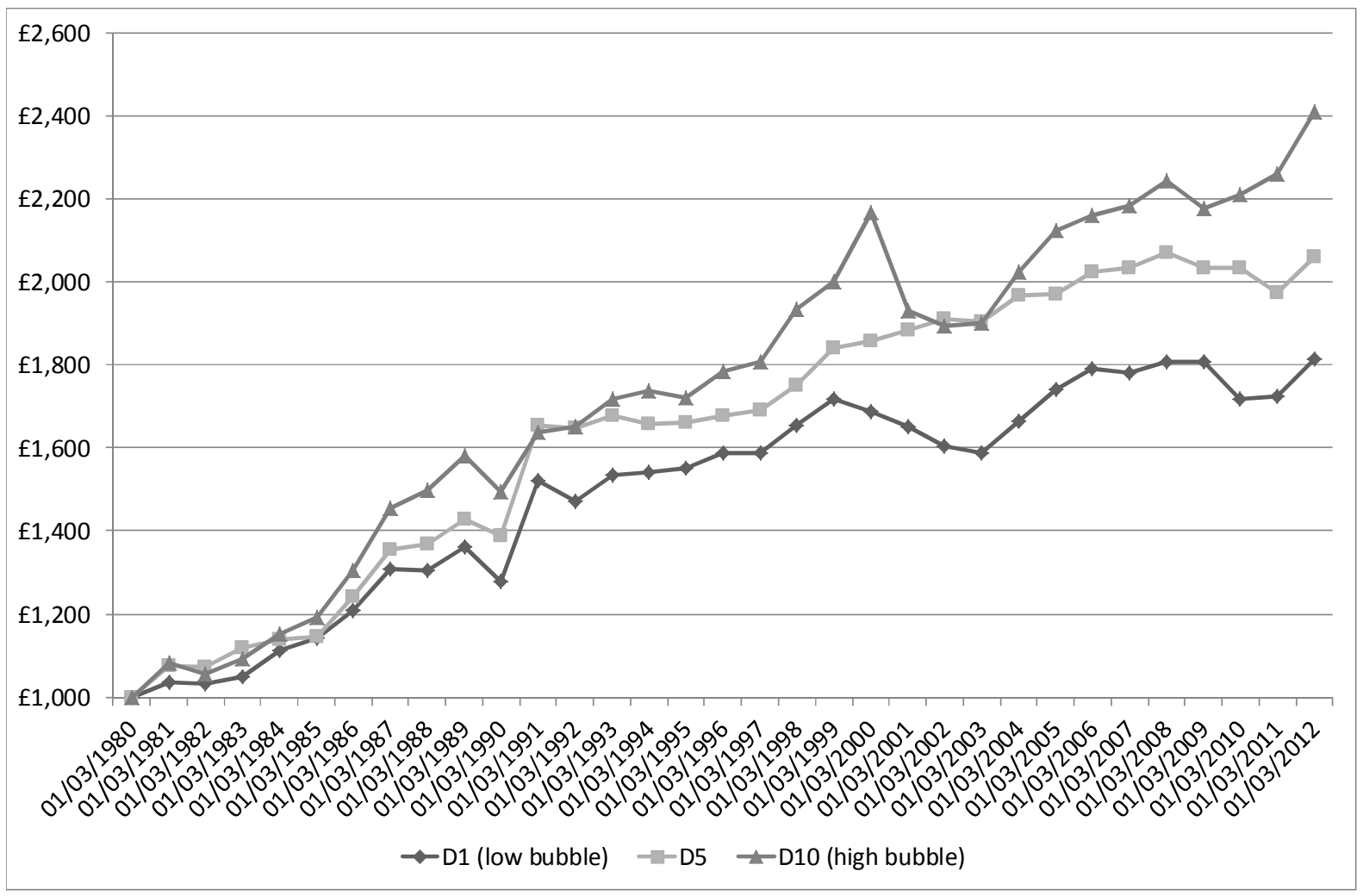

We then implement a variant of the two-step methodology of Fama and MacBeth (1973). In the first step we estimate a time-series version of the Carhart (1997) 4-factor model, but also including the bubble term as described above:

$$
R_{i, t}=\alpha+\beta_{M} R M R F_{i, t}+\beta_{S} S M B_{i, t}+\beta_{V} H M L_{i, t}+\beta_{U} U M D_{i, t}+\beta_{B} B B M S B_{i t}+v_{i, t}
$$

where $R_{i t}$ are the returns on the portfolios $i$ in each month $t$. Following Fama and French (1993), we employ 25 two-way size and book-to-market-sorted portfolios. We also separately employ the 27 portfolios that are three-way sorted on size, book-to-market and 
momentum constructed by Gregory et al. (2009). ${ }^{7} R M R F, S M B, H M L$ and $U M D$ are the factor mimicking portfolio returns for market excess returns (the return on a stock index less the risk-free rate proxy), firm size ("small-minus-big"), value ("high-minus-low" based on the market-to-book value) and momentum ("up-minus-down") respectively. If we examine the sizes of the correlations between $B B M S B$ and other factors using the entire sample period they are -0.04 with $R M R F,-0.12$ with $S M B,-0.10$ with $H M L$ and 0.02 with $U M D$, thus demonstrating the separation of the bubble factor from the others and that it is picking up different features of the returns data.

We initially estimate model (8) using the first five years of data, from October 1980 to September 1985, and in the second step, we use the factor loadings in a cross-sectional regression for October 1985:

$$
R_{i, t}=\alpha+\lambda_{M} \beta_{M}+\lambda_{S} \beta_{S}+\lambda_{V} \beta_{V}+\lambda_{U} \beta_{U}+\lambda_{B} \beta_{B}+e_{i, t}
$$

We then roll the sample forward by one month and estimate a new set of betas for November 1980 to October 1985 for use in a cross-sectional regression using these betas and the sorted portfolios for November 1985. This process continues until the sorted portfolio data, which end in December 2010, are exhausted, which provides 303 data points. $^{8}$ We can interpret the second stage regression parameters, $\lambda_{M}, \lambda_{S}, \lambda_{V}, \lambda_{U}, \lambda_{B}$ as factor risk premia, and the latter parameter is clearly of most direct interest.

\subsection{Results from Estimation of Bubble Factor Loadings and Risk Premia}

Table 4 presents the factor loadings on the standard four factors plus that for the factormimicking portfolio of the bubble, $B B M S B$ in the context of the separate first-pass regressions for the 25 size- and BTM-sorted portfolios. The table presents the parameter estimates from the time-series regression for each portfolio on the left hand side and the corresponding $t$-ratios on the right hand side. So growth stocks are represented towards the left of the table, while they have increasing value characteristics as we move to the right. As

\footnotetext{
${ }^{7}$ These data were obtained from their web site at http://business-school.exeter.ac.uk/research/areas/centres/xfi/research/famafrench/files//

${ }^{8}$ For comparison, we also run this regression including only a constant and the bubble and also excluding the bubble. However, these results do not add any additional insights compared to the composite regression and so are not shown.
} 
expected, the small and value stock portfolios load positively on the SMB and HML factors respectively. All of the portfolios have similar loadings on the market risk premium RMRF, indicating that it is not a good discriminator between different equity styles. There are no clear patterns in the loadings on the momentum factor (UMD), except that small growth stocks tend to load positively while all others have negative relationships with the factor, thus confirming previous research noting the failure of the Fama-French approach to capture relative strength. Considering the bubble factor in the second panel, like those of the momentum factor, there are no very strong patterns, and indeed most of the parameter estimates are not statistically significant at even the $10 \%$ level. It does appear to be the case, however, that growth stocks load more heavily on the bubble factor than value stocks, although there is no size effect. 
Table 4: Factor Loadings from Time-series Regression for Model including Bubble Term

Parameter estimates

t-ratios

\begin{tabular}{|c|c|c|c|c|c|c|c|c|c|c|}
\hline Size & Low & 2 & 3 & 4 & High & Low & 2 & 3 & 4 & High \\
\hline \multicolumn{11}{|l|}{ Alpha } \\
\hline Small & $0.006 * *$ & $0.006 * *$ & $0.008 * *$ & $0.009 * *$ & $0.009 * *$ & 2.667 & 3.743 & 5.932 & 5.215 & 5.858 \\
\hline 2 & $0.004^{* *}$ & $0.005^{* *}$ & $0.006 * *$ & $0.007 * *$ & $0.007 * *$ & 2.241 & 4.114 & 3.792 & 4.423 & 3.822 \\
\hline 3 & $0.005^{* *}$ & $0.004 * *$ & $0.006 * *$ & $0.006 * *$ & $0.009 * *$ & 2.898 & 3.669 & 3.733 & 4.293 & 5.805 \\
\hline 4 & $0.006^{* *}$ & $0.006 * *$ & $0.007 * *$ & $0.008^{* *}$ & $0.009 * *$ & 3.967 & 4.340 & 5.845 & 5.307 & 4.828 \\
\hline Big & $0.007 * *$ & $0.005^{* *}$ & $0.005^{* *}$ & $0.007 * *$ & $0.007 * *$ & 5.525 & 3.110 & 3.916 & 4.589 & 5.368 \\
\hline \multicolumn{11}{|c|}{ Beta bubble } \\
\hline Small & 0.010 & -0.0001 & 0.008 & $-0.103 * *$ & -0.073 & 0.157 & -0.002 & 0.263 & -2.964 & -1.718 \\
\hline 2 & 0.014 & -0.031 & -0.047 & -0.010 & -0.044 & 0.286 & -0.494 & -1.135 & -0.148 & -0.718 \\
\hline 3 & 0.060 & 0.026 & 0.006 & -0.018 & -0.066 & 1.079 & 0.870 & 0.164 & -0.454 & -1.244 \\
\hline 4 & 0.027 & 0.022 & -0.033 & -0.019 & -0.039 & 0.623 & 0.554 & -0.796 & -0.490 & -0.986 \\
\hline Big & -0.040 & 0.007 & 0.008 & -0.055 & 0.067 & -0.984 & 0.209 & 0.221 & -1.781 & 1.511 \\
\hline \multicolumn{11}{|c|}{ Beta $S M B$} \\
\hline Small & $1.072^{* *}$ & $1.000^{* *}$ & $0.839 * *$ & $0.769 * *$ & $0.746 * *$ & 17.921 & 17.760 & 12.836 & 7.031 & 9.207 \\
\hline 2 & $0.916^{* *}$ & $0.741^{* *}$ & $0.650 * *$ & $0.723 * *$ & $0.714^{* *}$ & 9.467 & 10.235 & 5.818 & 7.477 & 6.679 \\
\hline 3 & $0.883^{* *}$ & 0.546 & $0.554^{* *}$ & $0.465^{* *}$ & $0.740 * *$ & 16.578 & 0.074 & 5.331 & 4.371 & 10.331 \\
\hline 4 & $0.537^{* *}$ & $0.389 * *$ & $0.301^{* *}$ & $0.405^{* *}$ & $0.360 * *$ & 7.712 & 6.953 & 4.925 & 6.022 & 3.798 \\
\hline Big & $-0.216^{*}$ & $-0.146 * *$ & -0.013 & $-0.192 * *$ & $-0.364 * *$ & -2.492 & -2.715 & -0.325 & -4.115 & -5.374 \\
\hline \multicolumn{11}{|c|}{ Beta $H M L$} \\
\hline Small & $-0.360 * *$ & $-0.258^{* *}$ & -0.039 & 0.107 & $0.262 *$ & -7.143 & -2.920 & -0.424 & 0.750 & 2.175 \\
\hline 2 & $-0.584^{* *}$ & -0.114 & 0.036 & 0.110 & $0.391^{* *}$ & -5.957 & 0.085 & 0.297 & 0.938 & 3.750 \\
\hline 3 & $-0.631^{* *}$ & -0.151 & 0.058 & $0.266^{*}$ & $0.470^{* *}$ & -4.742 & -1.688 & 0.469 & 2.080 & 5.735 \\
\hline 4 & $-0.479 * *$ & -0.106 & $0.132 *$ & $0.210 * *$ & $0.358^{* *}$ & -4.159 & -1.841 & 2.029 & 2.881 & 2.965 \\
\hline Big & $-0.408 * *$ & $-0.124^{*}$ & 0.048 & $0.250 * *$ & $0.531^{* *}$ & -3.663 & -2.491 & 1.082 & 3.887 & 5.865 \\
\hline \multicolumn{11}{|c|}{ Beta UMD } \\
\hline Small & 0.086 & -0.040 & -0.008 & -0.022 & -0.053 & 1.867 & -0.789 & -0.139 & -0.360 & -0.904 \\
\hline 2 & 0.064 & -0.064 & -0.081 & -0.056 & $-0.089 *$ & 0.895 & -0.953 & -1.130 & -0.774 & -2.048 \\
\hline 3 & -0.020 & -0.088 & -0.024 & -0.137 & $-0.124^{*}$ & -0.201 & -1.558 & -0.319 & -1.790 & -2.450 \\
\hline 4 & 0.057 & -0.047 & -0.049 & $-0.131 * *$ & $-0.192 * *$ & 1.171 & -0.951 & -0.773 & -3.712 & -2.651 \\
\hline Big & -0.012 & -0.008 & 0.061 & $0.077^{* *}$ & -0.022 & -0.181 & -0.156 & 0.969 & 2.674 & -0.202 \\
\hline \multicolumn{11}{|c|}{ Beta $R M R F$} \\
\hline Small & $1.004^{* *}$ & $0.830 * *$ & $0.797^{* *}$ & $0.829 * *$ & $0.814^{* *}$ & 29.670 & 21.480 & 20.212 & 23.777 & 26.251 \\
\hline 2 & $1.036 * *$ & $0.936 * *$ & $0.878 * *$ & $0.973 * *$ & $0.972 * *$ & 21.626 & 27.603 & 23.674 & 24.413 & 32.469 \\
\hline 3 & $1.111^{* *}$ & $1.062 * *$ & $1.015^{* *}$ & $1.017^{* *}$ & $1.046^{* *}$ & 18.413 & 35.547 & 18.674 & 28.426 & 20.842 \\
\hline 4 & $1.093 * *$ & $1.055^{* *}$ & $1.032 * *$ & $1.134^{* *}$ & $1.096 * *$ & 27.592 & 28.635 & 33.402 & 35.332 & 27.985 \\
\hline Big & $0.886 * *$ & $0.954 * *$ & $1.053^{* *}$ & $1.023^{* *}$ & $0.898 * *$ & 19.633 & 28.676 & 25.812 & 24.687 & 21.165 \\
\hline \multicolumn{11}{|c|}{ Adjusted $R^{2}$} \\
\hline Small & 0.797 & 0.751 & 0.816 & 0.818 & 0.846 & & & & & \\
\hline 2 & 0.760 & 0.732 & 0.707 & 0.736 & 0.792 & & & & & \\
\hline 3 & 0.787 & 0.785 & 0.758 & 0.766 & 0.785 & & & & & \\
\hline 4 & 0.775 & 0.773 & 0.771 & 0.767 & 0.766 & & & & & \\
\hline Big & 0.792 & 0.767 & 0.795 & 0.782 & 0.710 & & & & & \\
\hline
\end{tabular}

Notes: Estimation over whole sample using OLS with heteroscedasticity and autocorrelation-consistent standard errors. The model is

$R_{i, t}=\alpha+\beta_{M} R M R F_{i, t}+\beta_{S} S M B_{i, t}+\beta_{V} H M L_{i, t}+\beta_{U} U M D_{i, t}+\beta_{B} B B M S B_{i t}+v_{i, t}$,

where $R_{i t}$ are the returns on the portfolios $i$ in each month t. RMRF, SMB, HML,UMD and BBMSB are the factor mimicking portfolio returns for market excess returns, firm size, value, momentum and stock-level bubbles respectively; ${ }^{*}$ and ${ }^{* *}$ denote statistical significance at the $5 \%$ and $1 \%$ levels respectively. 
The second stage cross-sectional regression results are presented in Table 5 . Here, the factor loadings (betas) from the first stage are used as regressors to explain the variation across the 25 two-way sorted or 27 three-way sorted portfolios for the whole sample and for the same sub-samples as those presented in Table 2 . The most salient feature of the results is that none of the factor loadings are able to significantly explain the cross-sectional variation in returns. The momentum term is marginally significant in the two-way sort, but none of the other factor risk premia is statistically important and in some cases they have the wrong signs. Thus, we find, like Gregory et al. (2009), that none of the four conventional factors are priced in the three-way sorted portfolios, and only one is in the two-way sort. This reflects the emerging consensus (see also Fletcher, 2010) that asset pricing models of these sorts simply do not work well in the UK context. What Fama and French $(1993 ; 1996)$ effectively show is that the model works well in capturing the variation that it was designed to explain - when stocks are sorted into portfolios according to size and the book-to-market ratio, the size and book-to-market factors are almost tautologically able to explain the differences in returns between those portfolios better than any other factors.

How, then, can we reconcile the results of Table 2, where the bubble term appears to be a priced risk factor, with those of Table 5, where it does not? One key difference is that the former are based on cross-sectional regressions at the firm level whereas the latter use the sorted portfolios. Thus it may be the case that all of the interesting variation occurs within the sorted portfolios rather than across them, so that it is lost in the regressions of Table 5 . 
Table 5: Risk Premia for the CAPM and Fama-French Specifications including a Bubble Term to explain 3-Way and 2-Way Sorted Portfolios of Stocks

\begin{tabular}{|c|c|c|c|c|c|c|c|}
\hline \multicolumn{7}{|c|}{ Panel A: Whole Sample October 1980 - December 2010 (363 points) } & \multirow[b]{2}{*}{$R^{2}$} \\
\hline & $\lambda_{0}$ & $\lambda_{M}$ & $\lambda_{s}$ & $\lambda_{v}$ & $\lambda_{u}$ & $\lambda_{B}$ & \\
\hline \multirow[t]{2}{*}{ 3-way sort } & 0.009 & 0.001 & 0.0010 & 0.003 & 0.002 & -0.004 & \multirow[t]{2}{*}{0.40} \\
\hline & $(0.003) * * *$ & $(0.003)$ & $(0.0022)$ & $(0.002)$ & $(0.003)$ & $(0.005)$ & \\
\hline \multirow[t]{2}{*}{ 2-way sort } & 0.006 & 0.004 & 0.0004 & 0.005 & 0.006 & -0.004 & \multirow[t]{3}{*}{0.41} \\
\hline & $(0.003)^{*}$ & $(0.004)$ & $(0.0021)$ & $(0.002)^{* * *}$ & $(0.004)^{*}$ & (0.005) & \\
\hline \multicolumn{7}{|c|}{ Panel B: Sub-sample January 1990 - December 2010 (252 points) } & \\
\hline & $\lambda_{0}$ & $\lambda_{M}$ & $\lambda_{s}$ & $\lambda_{v}$ & $\lambda_{u}$ & $\lambda_{B}$ & $R^{2}$ \\
\hline \multirow[t]{2}{*}{ 3-way sort } & 0.006 & 0.002 & 0.0012 & 0.002 & 0.003 & -0.003 & \multirow[t]{2}{*}{0.40} \\
\hline & $(0.003)^{*}$ & $(0.004)$ & $(0.0025)$ & $(0.003)$ & $(0.004)$ & $(0.006)$ & \\
\hline \multirow[t]{2}{*}{ 2-way sort } & 0.002 & 0.007 & 0.0004 & 0.004 & 0.008 & 0.797 & \multirow[t]{3}{*}{0.41} \\
\hline & $(0.004)$ & $(0.004)$ & $(0.0024)$ & $(0.003)$ & $(0.004)^{* *}$ & (0.068) & \\
\hline \multicolumn{7}{|c|}{ Panel C: Sub-sample January 2000 - December 2010 (147 points) } & \\
\hline & $\lambda_{0}$ & $\lambda_{M}$ & $\lambda_{s}$ & $\lambda_{v}$ & $\lambda_{u}$ & $\lambda_{B}$ & $R^{2}$ \\
\hline \multirow[t]{2}{*}{ 3-way sort } & 0.009 & -0.005 & 0.0034 & 0.006 & -0.004 & -0.003 & \multirow[t]{2}{*}{0.38} \\
\hline & $(0.003)^{* * *}$ & $(0.004)$ & $(0.0042)$ & $(0.005)$ & $(0.006)$ & (0.009) & \\
\hline \multirow[t]{2}{*}{ 2-way sort } & 0.0004 & -0.399 & -0.0013 & 0.010 & 0.007 & -0.006 & \multirow[t]{2}{*}{0.38} \\
\hline & $(0.004) * * *$ & $(0.475)$ & (0.0039) & $(0.004)^{* *}$ & $(0.006)$ & (0.009) & \\
\hline
\end{tabular}

Notes: $*, * *$ and $* * *$ denote significance at the $10 \%, 5 \%$, and $1 \%$ levels respectively. The stocks are valueweighted within the portfolios. The reported $R^{2}$ is the average over the cross-sectional regressions. We initially estimate the model using the first five years of data, from October 1980 to September 1985, and in the second step, we use the factor loadings in a cross-sectional regression for October 1985: $R_{i, t}=\alpha+\lambda_{M} \beta_{M}+\lambda_{S} \beta_{S}+\lambda_{V} \beta_{V}+\lambda_{U} \beta_{U}+\lambda_{B} \beta_{B}+e_{i, t}$

We then roll the sample forward by one month and estimate a new set of betas for November 1980 to October 1985 for use in a cross-sectional regression using these betas and the sorted portfolios for November 1985. This process continues until the sorted portfolio data, which end in December 2010, are exhausted, which provides 303 data points.

\section{The Bubble CAPM}

\subsection{Decomposing Beta into Fundamental and Bubble Betas}

In this sub-section we demonstrate how the fundamental and bubble betas are derived, and why they are independent of each other. Returning to the partition of the stock price into its fundamental and bubble components, taking equation (2), dropping the $i$ subscript for convenience and subtracting one from each time subscript yields:

$$
p_{t-1}^{a}=p_{t-1}^{f}+b_{t-1}+u_{t-1}
$$

Now subtract (10) from (2), divide both sides by the actual price at time $t-1, p_{t}^{a}$, and set the error terms equal to their expected value of zero:

$$
\frac{p_{t}^{a}-p_{t-1}^{a}}{p_{t-1}^{a}}=\frac{p_{t}^{f}-p_{t-1}^{f}}{p_{t-1}^{a}}+\frac{b_{t}-b_{t-1}}{p_{t-1}^{a}}
$$


The term on the left hand side of (11) is just the usual proportional simple return, which we could denote by $R$, while terms on the right could be defined as the fundamental and bubble returns, both expressed as a proportion of the actual price:

$$
r_{t}^{a}=r_{t}^{f}+r_{t}^{b}
$$

Let us now focus on the standard unconditional CAPM of Sharpe (1964) and Lintner (1965) that describes the relationship between the expected return on a stock, $E\left(R_{i}\right)$ and its level of market risk $\left(\beta_{i}\right)$ :

$$
E\left(R_{i}\right)=R_{f}+\beta_{e}\left\lfloor E\left(R_{m}\right)-R_{f}\right\rfloor
$$

We suppress time subscripts for simplicity and assume that the model holds period-byperiod. Now suppose that bubbles exist at both the individual stock level and thus "bubble risk" is partly systematic (varies along with the size of the market-wide bubble) and partly idiosyncratic. The total return on a stock $i$ is the sum of the fundamental return and of the bubble return. The return on the market portfolio can be defined similarly:

$$
R_{i}=R_{i}^{f}+R_{i}^{B} \text { and } R_{m}=R_{m}^{f}+R_{m}^{B}
$$

Given the separation of returns into the fundamental and non-fundamental components in equations (14), we can express the beta for stock $i$ as

$$
\beta_{i}=\frac{\operatorname{Cov}\left(R_{m}, R_{i}\right)}{\operatorname{Var}\left(R_{m}\right)}=\frac{\operatorname{Cov}\left(R_{m}^{f}+R_{m}^{B}, R_{i}^{f}+R_{i}^{B}\right)}{\operatorname{Var}\left(R_{m}^{f}+R_{m}^{B}\right)}
$$

Denoting the numerator in (15) as $A$ and the denominator as $B$, we can write

$$
A=\operatorname{Cov}\left(R_{m}^{f}, R_{i}^{f}\right)+\operatorname{Cov}\left(R_{m}^{f}, R_{i}^{B}\right)+\operatorname{Cov}\left(R_{m}^{B}, R_{i}^{f}\right)+\operatorname{Cov}\left(R_{m}^{B}, R_{i}^{B}\right)
$$

and

$$
B=\operatorname{Var}\left(R_{m}^{f}\right)+\operatorname{Var}\left(R_{m}^{B}\right)+2 \operatorname{Cov}\left(R_{m}^{f}, R_{m}^{B}\right)
$$

Assume also that the following restrictions hold:

$$
\operatorname{Cov}\left(R_{i}^{f}, R_{i}^{B}\right)=0, \operatorname{Cov}\left(R_{m}^{f}, R_{i}^{B}\right)=0, \operatorname{Cov}\left(R_{i}^{f}, R_{m}^{B}\right)=0, \operatorname{Cov}\left(R_{m}^{f} R_{m}^{B}\right)=0
$$


These restrictions are quite sensible since, by definition, the bubble component for both a stock and the market portfolio should be independent of its fundamentals and of each other's' fundamentals. $^{9}(16 a)$ and (16b) then simplify to

$$
A=\operatorname{Cov}\left(R_{m}^{f}, R_{i}^{f}\right)+\operatorname{Cov}\left(R_{m}^{B}, R_{i}^{B}\right)
$$

and

$$
B=\operatorname{Var}\left(R_{m}^{f}\right)+\operatorname{Var}\left(R_{m}^{B}\right)
$$

Finally, we can write the beta from (15) as

$$
\beta_{i}=\frac{\operatorname{Cov}\left(R_{m}^{f}, R_{i}^{f}\right)+\operatorname{Cov}\left(R_{m}^{B}, R_{i}^{B}\right)}{\operatorname{Var}\left(R_{m}^{f}\right)+\operatorname{Var}\left(R_{m}^{B}\right)}=\frac{\operatorname{Cov}\left(R_{m}^{f}, R_{i}^{f}\right)+\operatorname{Cov}\left(R_{m}^{B}, R_{i}^{B}\right)}{\operatorname{Var}\left(R_{m}\right)}=\beta_{i}^{f}+\beta_{i}^{B}
$$

where the fundamental beta, $\beta_{i}^{f}$ and bubble beta, $\beta_{i}^{B}$ are defined respectively as:

$$
\beta_{i}^{f}=\frac{\operatorname{Cov}\left(R_{m}^{f}, R_{i}^{f}\right)}{\operatorname{Var}\left(R_{m}\right)}
$$

and

$$
\beta_{i}^{B}=\frac{\operatorname{Cov}\left(R_{m}^{B}, R_{i}^{B}\right)}{\operatorname{Var}\left(R_{m}\right)}
$$

We have thus decomposed the traditional CAPM beta into fundamental and bubble beta terms. The simplifying deletion of the covariance terms depends only on the basic definition of a bubble: that the bubbly part of the current valuation is detached from fundamentals.

\subsection{Results from the Bubble CAPM}

Table 6 presents the results from the second-stage Fama-MacBeth-style regressions that include the bubble and fundamental beta terms as defined in Section 5.1. The results are quite revealing, and show that the part of the beta based on fundamentals is statistically

\footnotetext{
${ }^{9}$ Note here that we explicitly focus on rational bubbles and rule out intrinsic bubbles of the type examined by Froot and Obstfeld (1991), which are a non-linear function of fundamentals.
} 
insignificant in all of the second pass cross-sectional regressions and the bubble beta coefficients become insignificant when the size, value and momentum terms are added in the final rows of each panel. However, the bubble terms are positive and highly significant in the pure CAPM regressions. We therefore support the finding of Fama and French (1992) in the US context and others in the UK context that the CAPM beta overall becomes insignificant with these extra four-factor model terms in the regressions. Nonetheless it is fair to say that these findings are indicative that correlated sentiment across stocks related to bubble formation is more important in driving the common variation in returns that can be attributed to market risk than co-movements caused by fundamentals. 
Table 6: Time-series of Cross-section Results for the Bubble Beta included in the CAPM and Fama-French Regressions

\begin{tabular}{|c|c|c|c|c|c|c|}
\hline \multicolumn{7}{|c|}{ Panel A: Whole Sample May 1980 - March 2012 (383 points) } \\
\hline Intercept & $\begin{array}{l}\text { Bubble } \\
\text { Beta }\end{array}$ & $\begin{array}{l}\text { Fundamental } \\
\text { Beta }\end{array}$ & Size & BVP & Mom & $\mathbf{R}^{2}$ \\
\hline $\begin{array}{l}0.957 \\
(0.250)^{* * *}\end{array}$ & $\begin{array}{l}0.202 \\
(0.083)^{* * *}\end{array}$ & - & - & - & - & 0.01 \\
\hline $\begin{array}{l}0.689 \\
(0.199)^{* * *}\end{array}$ & - & $\begin{array}{l}0.188 \\
(0.140)\end{array}$ & - & - & - & 0.02 \\
\hline $\begin{array}{l}0.771 \\
(0.196)\end{array}$ & $\begin{array}{l}0.083 \\
(0.037)^{* *}\end{array}$ & $\begin{array}{l}0.124 \\
(0.168)\end{array}$ & - & - & - & 0.03 \\
\hline $\begin{array}{l}0.862 \\
(0.280)^{* * *}\end{array}$ & $\begin{array}{l}0.005 \\
(0.035) \\
\end{array}$ & $\begin{array}{l}0.155 \\
(0.189) \\
\end{array}$ & $\begin{array}{l}0.00001 \\
(0.00001)\end{array}$ & $\begin{array}{l}-0.763 \\
(0.065)^{* * *}\end{array}$ & $\begin{array}{l}0.609 \\
(0.175)^{* * *}\end{array}$ & 0.07 \\
\hline \multicolumn{7}{|c|}{ Panel B: Sub-sample January 1990 - March 2012 (267 points) } \\
\hline Intercept & $\begin{array}{l}\text { Bubble } \\
\text { Beta }\end{array}$ & $\begin{array}{l}\text { Fundamental } \\
\text { Beta }\end{array}$ & Size & BVP & Mom & $\mathbf{R}^{2}$ \\
\hline $\begin{array}{l}0.450 \\
(0.296)\end{array}$ & $\begin{array}{l}0.239 \\
(0.109)^{* *}\end{array}$ & - & - & - & - & 0.01 \\
\hline $\begin{array}{l}0.128 \\
(0.215)\end{array}$ & - & $\begin{array}{l}0.240 \\
(0.195)\end{array}$ & - & - & - & 0.03 \\
\hline 0.266 & 0.134 & 0.160 & - & - & - & 0.04 \\
\hline$(0.213)$ & $(0.051)^{* * *}$ & $(0.233)$ & & & & \\
\hline 0.728 & 0.002 & 0.235 & 0.00003 & -1.067 & 0.437 & 0.06 \\
\hline$(0.327)^{* *}$ & $(0.048)$ & $(0.263)$ & $(0.00002)$ & $(0.085)^{* * *}$ & $(0.213)^{* *}$ & \\
\hline \multicolumn{7}{|c|}{ Panel C: Sub-sample January 2000 - March 2012 (147 points) } \\
\hline Intercept & $\begin{array}{l}\text { Bubble } \\
\text { Beta }\end{array}$ & $\begin{array}{l}\text { Fundamental } \\
\text { Beta }\end{array}$ & Size & BVP & Mom & $\mathbf{R}^{2}$ \\
\hline $\begin{array}{l}-0.076 \\
(0.416)\end{array}$ & $\begin{array}{l}0.326 \\
(0.176)^{* *}\end{array}$ & - & - & - & - & 0.01 \\
\hline-0.161 & - & 0.148 & - & - & - & 0.03 \\
\hline$(0.324)$ & & $(0.226)$ & & & & \\
\hline 0.125 & 0.145 & 0.026 & - & - & - & 0.04 \\
\hline$(0.310)$ & $(0.072)^{* *}$ & $(0.260)$ & & & & \\
\hline 1.272 & 0.020 & -0.008 & 0.000001 & -1.048 & -0.051 & 0.06 \\
\hline$(0.466)^{* * *}$ & (0.067) & $(0.323)$ & $(0.00001)$ & $(0.108)^{* * *}$ & (0.305) & \\
\hline
\end{tabular}

Notes: in the full model we run a series of cross-sectional regressions of the form

$R_{i, t}=\alpha+\beta_{1}$ BubbleBeta $_{i, t}+\beta_{2}$ FundamentalBeta $_{i, t}+\beta_{3} M V_{i, t}+\beta_{4} B V P_{i, t}+\beta_{5} M O M_{i, t}+u_{i, t}$ where $R$ are the monthly returns, BubbleBeta and FundamentalBeta are the decomposed values from the CAPM betas as described above, $M V$ are the market capitalisations, $B V P$ is the book-to-price ratio, MOM is the previous year's return for the stock to measure the extent to which it has momentum, and the subscripts denote firm $i$ and month $t$. The $\mathrm{R}^{2}$ figures presented are the averages over all of the crosssectional regressions for a given specification. 


\section{Conclusions}

This paper has shown how bubbles at the individual firm level and their covariances with bubbles at the level of the market as a whole may be important in driving stock returns. We reach several conclusions. First, we find that bubbles have a role to play in explaining the cross-sectional variation in returns and are priced, but in a fashion unrelated to the standard four factors that are popularly employed in asset pricing tests, and so they are unable to explain the variation in returns across size, value, and momentum sorted portfolios. There is some evidence that bubbles are a source of market-wide risk and in that sense are pervasive. Second, we show in a set of time-series of cross-section CAPM-style regressions for individual stocks that there is a positive and statistically significant bubble premium. Third, we show, again for a time-series of cross-sections on individual stocks, that when we separate the traditional CAPM beta into fundamental and bubble parts, the latter commands a positive and significant risk premium while the former is never significant. When we add the standard size, value and momentum factors to these regressions however, the bubble term becomes insignificant.

While the results presented here paint a mixed picture, they are encouraging and it is clear that there remains much work to do in more formally embedding bubble growth and collapse into both the theoretical asset pricing literature, and as a possible explanation for what are currently viewed as pricing anomalies. The rewards for doing so could be quite considerable, since the presence of speculative bubbles - and the risk that they may subsequently collapse - could be a driver of many phenomena in empirical asset pricing that are currently viewed as anomalies. For example, it is possible that out of phase bubbles at the individual stock level might be the cause of the long term reversals in prices first documented by De Bondt and Thaler (1985). Along these lines, stock returns would be high when the bubble is growing, with the subsequent reversal being explained by the bubble's collapse and overshoot followed initially by an undervaluation relative to fundamentals.

Further research could focus on the drivers of bubbles at the stock level, focusing in particular on the timing of bubble inception and collapse. The extent to which positive momentum may be driven by the slow growth of speculative bubbles, and negative momentum by their collapse, would be a fruitful area. It may be possible that knowledge of the existence of bubble deviations at the firm level could enable banks and securities firms 
to better manage their risks and investors to enhance their trading profits by screening out stocks where bubble collapse seems most likely, along the lines suggested by Brooks and Katsaris (2005b) at the index level.

\section{References}

Anderson, K., Brooks, C., and A. Katsaris (2010), 'Speculative bubbles in the S\&P 500: was the tech bubble confined to the tech sector?', Journal of Empirical Finance, 17, 345261.

Black, F., Jensen, M.C. and Scholes, M. (1972) 'The Capital Asset Pricing Model: Some Empirical Tests' in Jensen, M. (ed.) Studies in the Theory of Capital Markets (Praeger).

Brooks, C. and A. Katsaris (2005a), 'A three-regime model of speculative behaviour: modelling the evolution of bubbles in the S\&P 500 Composite Index', Economic Journal, 115 (505), 767-797.

Brooks, C. and A. Katsaris (2005b), 'Trading rules from forecasting the collapse of speculative bubbles for the S\&P 500 composite index', Journal of Business, 78 (5), 2003-2036.

Brooks, C. and A. Katsaris (2003), 'Rational speculative bubbles: an investigation of the London Stock Exchange', Bulletin of Economic Research, 55 (4), 319-346.

Bustos, S.M., Andersen, J.V., Miniconi, M., Nowak, A., Roszczynska-Kurasinka, M. and Brée, D. (2011) 'Pricing Stocks with Yardsticks and Sentiments' Algorithmic Finance, 1, 183190.

Chen, J., Hong, H. and Stein, J.C. (2001) 'Forecasting Crashes: Trading Volume, Past Returns and Conditional Skewness in Stock Prices', Journal of Financial Economics, 61, 345381.

Carhart, M. (1997) 'On the Persistence of Mutual Fund Performance', Journal of Finance, 52, 57-82.

Cochrane, J.H. (2003) 'Stocks as Money: Convenience Yield and the Tech-Stock Bubble' in Hunter, W.C., Kaufman, G.G., and Pomerleano, M. (eds.) Asset Price Bubbles, MIT Press, Cambridge, Mass.

Damodaran, A. 2000. The Dark Side of Valuation: Firms with no Earnings, no History and no Comparables: Can Amazon.com be Valued? Working paper, Stern School of Business.

DeBondt, W. and Thaler, R. (1985) 'Does the Stock Market Overreact?', Journal of Finance, 40, 793-805.

Dezhbakhsh, H. and A. Demirguc-Kunt (1990), 'On the presence of speculative bubbles in stock prices', Journal of Financial and Quantitative Analysis, 25 (1) 101-112.

Diba, B.T. and Grossman, H.I. (1988) 'The Theory of Rational Bubbles in Stock Prices', Economic Journal, 98, 746-54.

Donaldson G. R., Kamstra M. (1996) 'A New Dividend Forecasting Procedure That Rejects Bubbles in Asset Prices: The Case of 1929's Stock Crash', Review of Financial Studies, 9, 333-383.

Ferson, W.E. and Harvey, C.R. (1993) 'The Risk and Predictability of International Equity Returns', Review of Financial Studies, 6, 527-566. 
Fama, E. F., and K. R. French (1992) 'The Cross-Section of Expected Stock Returns', Journal of Finance, 47, 427-465.

Fama, E. and French, K.R. (1993) 'Common Risk Factors in the Returns on Stocks and Bonds', Journal of Financial Economics, 33, 3-53.

Fama, E. and French, K.R. (1995) 'Size and Book-to-Market Factors in Earnings and Returns', Journal of Finance, 50, 131-155.

Fama, E. and French, K.R. (1996) 'Multifactor Explanations of Asset Pricing Anomalies', Journal of Finance, 51, 55-84.

Fama, E. F., and J. D., MacBeth. (1973) 'Risk, Returns, and Equilibrium: Empirical Tests', Journal of Political Economy, 81, 607-636.

Fletcher, J. (2010) 'Arbitrage and the Evaluation of Linear Factor Models in UK Stock Returns', Financial Review, 45, 449-468.

Froot, K.A. and Obstfeld, M. (1991) 'Intrinsic bubbles: The case of stock prices', American Economic Review, 81, 1189-1224.

Gregory, A., Tharyan, R., and Hung, A. (2009) 'The Fama-French and Momentum Portfolios and Factors in the UK', Working paper 09/05, Xfi Centre for Finance and Investment,University of Exeter, UK.

Hardouvelis, G.A. (1988) 'Evidence on Stock Market Speculative Bubbles: Japan, the United States and Great Britain', Federal Reserve Bank of New York Quarterly Review, 4-16.

Harvey, C.R. (1991) 'The World Price of Covariance Risk' Journal of Finance 46, 111-153.

Hobijn, B. and Jovanovic B. (2001) 'The Information-Technology Revolution and the Stock Market: Evidence', American Economic Association Papers and Proceedings, 91, 1203-1220.

Hodrick, R. (1992) Dividend yields and expected stock returns: Alternative procedures for inference and measurement. Review of Financial Studies 5, 357-386.

Jegadeesh, N. and Titman, S. (1993) 'Returns to Buying Winners and Selling Losers: Implications for Stock Market Efficiency', Journal of Finance, 48, 65-91.

Keating, E.K., Lys, T.Z., and Magee, R.P. (2003) 'Internet Downturn: Finding Valuation Factors in Spring 2000' Journal of Accounting and Economics 34, 189-236.

Kindleberger, C.P., (1989) 'Manias, Panics and Crashes: A History of Financial Crises', Macmillan, London.

Kothari, S.P. and Shanken, J. (1997) 'Book-to-market, dividend yield, and expected market returns: A time-series analysis', Journal of Financial Economics 44, 169-203.

Lintner, J. (1965) 'The Valuation of Risky Assets and the Selection of Risky Investments in Stock Portfolios and Capital Budgets', Review of Economics and Statistics, 47, 13-37.

McQueen, G. and Thorley, S. (1994) 'Bubbles, Stock Returns, and Duration Dependence', Journal of Financial and Quantitative Analysis, 29, 379-401.

Merton, R.C. (1973) 'An intertemporal capital asset pricing model', Econometrica, 41, 867887.

Pastor, L. and Veronesi, P. (2006) 'Was there a NASDAQ Bubble in the Late 1990s?' Journal of Financial Economics 81, 61-100.

Petkova, R. (2006) 'Do the Fama-French Factors Proxy for Innovations in Predictive Variables?' Journal of Finance, 61, 581-612.

Santoni G. J. (1987) 'The Great Bull Markets 1924-29 and 1982-87: Speculative Bubbles or Economic Fundamentals?', Federal Reserve Bank of St. Louis, Nov., 16-29.

Sharpe, W. F. (1964) 'Capital asset prices: A Theory of Market Equilibrium under Conditions of Risk', Journal of Finance, 19, 425-442. 
Shiller, R.J. (1981)'Do Stock Prices Move too Much to be Justified by Subsequent Changes in Dividends', American Economic Review, 71, 421-36.

Shiller, R.J. (2000) 'Irrational Exuberance', Princeton University Press, Princeton, New Jersey. Van Norden S. (1996). 'Regime Switching as a Test for Exchange Rate Bubbles', Journal of Applied Econometrics, 11, 219-51.

Van Norden, S. and Schaller, H., (1999) 'Speculative Behaviour, Regime-Switching and Stock Market Crashes', in Non-Linear Time Series Analysis of Economic and Financial Data, P. Rothman (ed.), Kluwer Academic Publishers, Boston.

Vassalou, M. and Xing, Y. (2004) 'Default Risk in Equity Returns', Journal of Finance, 59, 831868. 